\title{
Bem-estar animal em aulas de Bioclimatologia Animal
}

\author{
Matheus Ramalho de Lima, Ph.D.
}

Universidade Federal do Sul da Bahia, Brasil

Recibido: 25 de febrero del 2015 Aprobado: 15 de mayo del 2015

*Autor de correspondencia: Matheus Ramalho de Lima. Universidade Federal do Sul da Bahia. Praça Joana Angélica, Bela Vista, Teixeira de Freitas, Bahia, Brasil. Teléfono: (55 73) 4598-5188. Correo electrónico: mrlmatheus@gmail.com

Cómo citar este artículo: Ramalho de Lima M. Bem-estar animal em aulas de Bioclimatologia Animal. Spei Domus. 2015;11(22):57-61. doi: http://dx.doi.org/10.16925/sp.v11i22.1208

Resumo. Propósito: o objetivo desta revisão é abordar questões relacionadas ao ensino do Bem-estar Animal (BEA), com ênfase na situação brasileira, e discutir sobre os desafios e as possibilidades de aprimoramento Descrição: é essencial que estudantes de cursos voltados à ciência animal aprendam durante a graduação as bases conceituais do BEA e suas principais aplicações. Ponto de vista: embora recente, o ensino do BEA nas universidades brasileiras apresentou crescimento acentuado nos últimos anos, o que tem permitido a visualização de algumas características nacionais no ensino do BEA. Este, por sua vez, beneficia-se de maneira significativa da associação com a pesquisa na medida em que se trata de uma área de conhecimento em construção. Conclusões: os principais desafios que se apresentam no Brasil para o ensino do BEA são discutidos. Ao inserir o ensino do BEA em seus currículos, as universidades aumentam a adequação dos seus egressos ao mercado de trabalho atual e contribuem para um avanço na ética da relação ser humano-animal.

Palavras-chave: comportamento, desafios, ensino superior. 


\title{
Bienestar animal en clases de Bioclimatología Animal
}

Resumen. Propósito: el objetivo de esta revisión es abordar cuestiones relacionadas a la enseñanza del Bienestar Animal (BEA), con énfasis en el caso brasileño, y discutir acerca de los retos y las posibilidades de perfeccionamiento. Descripción: es esencial que estudiantes de cursos de la ciencia animal aprendan en el pregrado las bases conceptuales del BEA y sus principales aplicaciones. Punto de vista: si bien recientemente la enseñanza del BEA en las universidades brasileñas ha presentado un crecimiento acentuado en los últimos años, lo que ha permitido la visualización de algunas características nacionales en la enseñanza del BEA, este, a su turno, se beneficia de manera significativa de la asociación con la investigación en la medida que se trata de un área de conocimiento en construcción. Conclusiones: los principales retos presentados en Brasil en cuanto a la enseñanza del BEA son discutidos. $\mathrm{Al}$ introducir la enseñanza del BEA en sus currículos, las universidades incrementan la adecuación de sus egresos al mercado laboral actual y aportan al avance en la ética de la relación ser humano-animal.

Palabras clave: conducta, educación superior, retos.

\section{Animal welfare in Animal Bioclimatology classes}

\begin{abstract}
Purpose: the purpose of this review is to address issues related to the teaching of Animal Welfare (BEA), focusing on the Brazilian case, and discuss the challenges and possibilities for improvement. Description: it is essential that students of animal science courses in the undergraduate program learn the conceptual foundations and main applications of BEA. Point of view: while BEA teaching in Brazilian universities has had a marked growth in recent years and has allowed to identify some of its national characteristics, it in turn benefits significantly from the association with research as this is an area of knowledge under construction. Conclusions: the main challenges posed in terms of BEA teaching in Brazil are discussed. By introducing BEA teaching into their curricula, universities increase its graduates' suitability for current labor market and contribute to progress in the ethics of human-animal relationship.
\end{abstract}

Keywords: behavior, higher education, challenges. 


\section{Introdução}

É mais do que importante que os estudantes de cursos voltados à ciência animal aprendam, durante a sua formação na graduação, os conceitos e principais questionamentos sobre o bem-estar animal, especialmente em situações práticas nas quais o aluno possa entender e perceber momentos críticos nesse aspecto com mais facilidade. Há algum tempo no Brasil, a atenção a essas demandas de ordem de bem-estar têm sido valorizadas visto que o bem-estar é um momento pelo qual o animal está passando na tentativa de adaptar-se ao seu novo ambiente [1]. Espera-se que o médico veterinário, por exemplo, seja um profissional comprometido com o bem-estar e a saúde animal [2].

Embora tenhamos tido a iniciativa de adicionar essa temática na disciplina de Bioclimatologia Animal, a ementa não contempla muita atenção ao bem-estar animal. Os alunos geralmente têm uma disciplina de Etologia; contudo, tal ementa apresenta informações que não são de animais de produção, mas sim silvestres. Considerando essa lacuna, optei, na condição de docente responsável pela disciplina de Bioclimatologia Animal, introduzir mais informações aos alunos sobre práticas na parte de bem-estar animal no curso em questão.

Assim, elaboramos o planejamento de atividades práticas em uma granja de produção comercial de suínos para que os alunos pudessem conferir, in loco, os assuntos abordados em sala de aula no que concerne ao bem-estar animal, especificamente, as matrizes engaioladas na maternidade da granja. Essa prática levou em conta que sistemas intensivos de criação influenciam tanto na condição de conforto como do bem-estar dos animais, e que esses fatores afetam a capacidade de produção e reprodução dos suínos [3].

\section{Avaliação do bem-estar animal}

O ensino do bem-estar animal na disciplina de Bioclimatologia Animal no curso é de fundamental importância aos alunos para que possam se formar com conhecimentos específicos e se tornar profissionais capazes de entender que os animais não são máquinas, mas sim seres sencientes, que precisam de cuidados e condições para que possam promover o melhor ganho nas melhores condições de vida.
Além disso, hoje a ciência considera o bem-estar animal como um dos principais fatores que podem influenciar o resultado de um experimento e valorizase o uso ético dos animais ao retomar o princípio dos três R’s desenvolvido por Russell e Burch [4].

A disciplina ministrada foi Bioclimatologia Animal e o assunto escolhido, devido às limitações de estrutura de laboratórios e opções na região, para avaliar o bem-estar animal e correlacionar com o abordado em sala de aula foi o bem-estar de matrizes paridas em maternidade de uma granja de suínos.

\section{A estratégia adotada}

A estratégia adotada se deu em virtude da necessidade de aproximação da Universidade com a produção industrial, o que fez com que decidíssemos incluir uma avaliação in loco os assuntos abordados em sala de aula. O modelo foi bem-sucedido, pois aliou a parte teórica com a prática, e tornou os alunos mais conscientes do assunto e da importância de se entender e avaliar o bem-estar animal.

Os alunos apresentavam dificuldade em entender certos assuntos práticos e o uso de uma avaliação diretamente na granja, que considerasse todos os aspectos da produção, tornou a experiência bem exitosa e fez dos alunos pessoas mais conscientes no que concerne ao bem-estar animal.

Além disso, os alunos tiveram a iniciativa de imitar a situação dos animais ali alojados. Foi uma escolha deles. Em cada equipe, um aluno ficou por dez minutos dentro de uma gaiola vazia de matriz e, disso, tirou suas impressões mais do que pessoais. Esse gesto logicamente não tem aval científico nem considera as dimensões e densidade semelhantes em que a matriz convive nessa instalação, mas possibilitou aos alunos uma constatação até então não considerada por eles: os animais sofrem em ver as pessoas e outros animais livres, ali, perto deles, enquanto eles estão presos. Segundo os alunos, essa situação os deixou estressados e com uma sensação de serem prisioneiros e de impotência. Também perceberam, por já ter o conhecimento da produção de suínos e da nutrição desses animais, que essa situação pode promover efeitos colaterais diversos na produção devido a uma situação estressora já que o animal infeliz não consegue lidar com situações angustiantes, o que resulta em alterações fisiológicas e comportamentais. Portanto, animais estressados poderão ter seu sistema imunológico comprometido e serão impróprios para utilização em pesquisas [5]. 
Assim, a avaliação planejada na avaliação do bem-estar das matrizes in loco era apenas a mensuração de comportamento, mas com a iniciativa e a vontade dos alunos de "sentir na pele" o que o animal sente (ainda que uma aproximação), tornou a experiência mais do que exitosa, pois lhes possibilitou considerar que não basta só produzir, mas também dar boas condições de vida aos animais.

\section{Metodologia de avaliação}

Os alunos tinham planilhas de comportamento que eram utilizadas a cada cinco minutos. As avaliações foram feitas de acordo com o apresentado na Tabela 1.

Tabela 1. Variáveis comportamentais durante a avaliação

\begin{tabular}{|c|c|}
\hline Variável & Descrição \\
\hline $\begin{array}{l}\text { Utilização do } \\
\text { bebedouro }\end{array}$ & $\begin{array}{l}\text { Tempo em minutos e número de vezes } \\
\text { em que a porca acionou o bebedouro } \\
\text { consumindo água ou não. }\end{array}$ \\
\hline $\begin{array}{l}\text { Permanência no } \\
\text { comedouro }\end{array}$ & $\begin{array}{l}\text { Tempo em minutos e número de vezes } \\
\text { em que a porca permaneceu com a } \\
\text { cabeça dentro do comedouro realizando } \\
\text { ou fuçando a alimentação. }\end{array}$ \\
\hline $\begin{array}{l}\text { Porca } \\
\text { amamentando }\end{array}$ & $\begin{array}{l}\text { Tempo em minutos e número de vezes } \\
\text { que a porca amamentou; a amamen- } \\
\text { tação foi considerada quando a porca } \\
\text { deita e os leitões vão ao encontro dela; } \\
\text { termina no momento em que os leitões } \\
\text { se satisfizeram e saem de perto da porca, } \\
\text { até ter dois leitões mamando. } \\
\text { Leitões que dormiram próximo à glân- } \\
\text { dula mamária não foram considerados } \\
\text { como tempo em amamentação. }\end{array}$ \\
\hline Porca deitada & $\begin{array}{l}\text { Tempo em minutos em que a porca per- } \\
\text { maneceu completamente deitada sobre } \\
\text { o abdômen ou lateralmente. }\end{array}$ \\
\hline Porca em pé & $\begin{array}{l}\text { Tempo em minutos em que a porca } \\
\text { esteve completamente em pé, sobre os } \\
\text { quatro pés. }\end{array}$ \\
\hline $\begin{array}{l}\text { Outros tipos de } \\
\text { postura }\end{array}$ & $\begin{array}{l}\text { Tempo em minutos em que a porca } \\
\text { esteve sentada, ajoelhada e/ou em outras } \\
\text { posições. }\end{array}$ \\
\hline
\end{tabular}

Fonte: elaboração própria

Câmeras foram instaladas para verificação posterior devido a que a avaliação e os controles interativos do conforto térmico dos suínos pela análise de imagem superam os problemas inerentes ao método convencional, pois se utiliza o próprio animal como um biossensor em resposta aos reflexos do ambiente por meio da análise comportamental [6]. Assim, relativamente à coleta de informações sobre os aspectos comportamentais, a técnica mais utilizada e disseminada tem sido a utilização de câmeras que filmam permanentemente o comportamento dos animais. Essa técnica permite o monitoramento dos animais de maneira relativamente simples e com menor interferência da presença do ser humano sobre o comportamento dos animais.

Os dados foram mensurados e apresentados em sala de aula como trabalho da disciplina. A parte dos alunos, iniciativa deles após a avaliação das matrizes, foi incluída na apresentação como forma de comentários adicionais, em que eles mostraram a perspectiva sobre a situação avaliada.

\section{O impacto nos alunos}

O impacto foi imediato. $\mathrm{O}$ aprendizado e o interesse no assunto em sala de aula se tornaram maiores, especialmente porque os alunos passaram por situação semelhante à qual os animais são constantemente submetidos.

O interesse pelo bem-estar animal aumentou e os alunos tornaram-se mais críticos e interessados não só nessa prática, mas também queriam "repetir a dose" em outras situações da produção animal, como os troncos de contenção, os currais, os piquetes etc.

A experiência da prática aliada à teoria tornou a disciplina muito exitosa e o desempenho e aprendizado dos alunos foi excelente. Além disso, após a finalização do curso, os alunos buscaram mais informações sobre o assunto e manifestaram seu interesse em fazer especializações na área e aplicar o aprendido em outras disciplinas. Pôde-se constatar que conhecer as peculiaridades fisiológicas que se relacionam com a dor e o estresse animal, somadas às questões ético-filosóficas de direito à vida com dignidade das espécies, alicerçam a importância da abordagem moral e ética no exercício da pesquisa animal [7].

\section{A estratégia poderia ser usada novamente?}

A mesma estratégia poderia ser usada novamente contanto que fossem adicionados mais detalhes e formas de considerar o bem-estar animal. Estimular os alunos, de forma já planejada, a vivenciarem as mesmas situações dos animais, de forma optativa, logicamente, também seria proposto. 
Quando se fala em bem-estar animal, devese considerar os conceitos expressos nas chamadas "cinco liberdades", listadas abaixo, e que foram abordadas em sala e no ambiente de avaliação na granja.

1. Ausência de fome e sede: por meio do acesso à água e a uma dieta que mantenha a saúde e o vigor dos animais.

2. Livres de dor, ferimentos ou doença: por meio da prevenção, do diagnóstico precoce e do tratamento rápido, devem ser evitados dor e sofrimentos desnecessários aos animais.

3. Ausência de desconforto: por meio de um ambiente apropriado, que inclui abrigo e uma área de descanso confortável.

4. Liberdade de expressar comportamento normal: proporcionando espaço suficiente, instalações apropriadas e companhia de animais da mesma espécie.

5. Ausência de medo ou sofrimento: assegurando condições para existirem alojamentos, maneio e pessoal.

Esses conceitos foram apresentados em sala de aula e foram consideradas as dificuldades e as limitações, mas também as vantagens de incluir em avaliações com animais. Os alunos, por sua vez, na avaliação in loco, observaram e puderam correlacionar as informações apresentadas em sala de aula com a prática; com isso, eles perceberam que alguns dados, como frequência respiratória, não remetem a um estresse de forma clara, bem como dados fisiológicos alterados, mas que o comportamento é um dos fatores que mais influenciam na avaliação do bem-estar animal de forma mais clara. Contudo, pode haver equivocação, especialmente se o avaliador não tiver conhecimento do comportamento natural ou adaptado do animal avaliado.

Essa experiência desenvolvida no âmbito da disciplina de Bioclimatologia Animal foi satisfatória e possibilitou a adequação de mais instrumentos para turmas futuras. Além disso, mostrou que é possível adicionar aspectos práticos nas aulas e nos ensinamentos aos alunos a fim de torná-los mais responsáveis pelo bem-estar animal e não formando alunos que pensam apenas na produção incessante de alimentos, produção animal.
O abordado nesta aplicação serve não só para alunos, mas claramente para quem trabalha ou convive com animais (de produção ou não), por tornálos mais conscientes de que o animal pensa, sente e avalia as melhores condições para sua melhor vida e, por isso, busca formas de se adaptar ao ambiente em que vive, mesmo que para isso deixe de apresentar comportamentos naturais específicos (da fase, da idade, do sexo). Com isso, não só os alunos são peças importantes nesse contexto, mas também todos os que convivem e trabalham com os animais.

\section{Agradecimentos}

Às estudantes de iniciação científica da Universidade Federal do Sul da Bahia: Lorena Pinheiro Miranda, Luciana Ravena Costa Silva e Tatiana Fraga Fonseca pela edição final do material.

\section{Referências}

[1] Broom DM. Indicators of poor welfare. British Veterinary Journal 1986;142:524-6.

[2] Broom DM, Molento CFM. Animal welfare: concept and related issues - Review. Archives of Veterinary Science 2004;9(2):1-11.

[3] Pandorfi H, Silva IJO da, Carvalho JL de, Piedade SMS. Estudo do comportamento bioclimático de matrizes suínas alojadas em baias individuais e coletivas, com ênfase no bem-estar animal na fase de gestação. Engenharia Rural 2006;17(1):1-10.

[4] Russell WMS, Burch RL. The principles of humane experimental technique. Londres: Methuen \& Co. Ltda.

[5] Frajblat M, Amaral VLL, Rivera EAB. Ciência em Animais de Laboratório. Ciência e Cultura, São Paulo, 2008;60(2):44-6.

[6] Xin H; Shao J. Real-time assessment of swine thermal comfort by computer vision. Em: Proceedings of the World Congress of Computers. In Agriculture and Natural Resources, 2. Proceedings... Foz do Iguaçu: American Society Agriculture Engineering; 2002.

[7] Crissiuma AL, Almeida ECP de. Experimentação e bem-estar animal: artigo de revisão. Saúde \& Ambiente em Revista 2006;1(2):1-10. 